\title{
Assessment of Knowledge, Attitude, and Practice about Biomedical Waste Management and Associated Factors among the Healthcare Professionals at Debre Markos Town Healthcare Facilities, Northwest Ethiopia
}

\author{
Teshiwal Deress $\mathbb{D}^{\mathrm{D}},{ }^{1}$ Fatuma Hassen, ${ }^{2}$ Kasaw Adane, ${ }^{1}$ and Aster Tsegaye ${ }^{2}$ \\ ${ }^{1}$ Unit of Quality Assurance and Laboratory Management, School of Biomedical and Laboratory Sciences, College of Medicine and \\ Health Sciences, University of Gondar, P.O. Box 196, Gondar, Ethiopia \\ ${ }^{2}$ Department of Medical Laboratory Sciences, School of Allied Health Sciences, College of Health Sciences, \\ Addis Ababa University, Addis Ababa, Ethiopia
}

Correspondence should be addressed to Teshiwal Deress; teshiwalderess@gmail.com

Received 27 February 2018; Revised 31 May 2018; Accepted 5 July 2018; Published 2 October 2018

Academic Editor: Issam Al-Khatib

Copyright (c) 2018 Teshiwal Deress et al. This is an open access article distributed under the Creative Commons Attribution License, which permits unrestricted use, distribution, and reproduction in any medium, provided the original work is properly cited.

\begin{abstract}
Background. Healthcare activities restore health and save lives at the same time; however, they can generate hazardous biomedical wastes to a human being or the environment. Generation and disposal of biomedical wastes have become an emerging problem worldwide. Objective. To assess knowledge, attitude, and practice about biomedical waste management and associated factors among healthcare professionals in Debre Markos town healthcare facilities, northwest Ethiopia. Methods. A cross-sectional study was employed, and data were collected through structured self-administered questionnaire and observational checklist. Data were entered into the Epi-data 3.1 software and exported into SPSS version 20 for analysis. Bivariate and multivariate logistic regression analyses were computed. Variables with a $P$ value of $<0.05$ in the multivariate logistic regression analysis were considered to explain the presence of statistically significant associations. Result. Among 296 healthcare professionals studied, 168 (56.8\%), 196 (66.2\%), and $229(77.4 \%)$ had adequate knowledge, favorable attitude, and adequate practice score, respectively. Regarding associated factors, MSc and $\mathrm{MD}^{+}$(AOR: 4, 95\% CI: (1.37, 149.52)), BSc holders (AOR: 2.53, 95\% CI: (1.47, 4.38)), and availability of color-coded bins (AOR: 7.68, 95\% CI: $(3.30,17.89)$ ) were identified more likely to contribute for adequate knowledge, favorable attitude, and adequate practice scores, respectively. Conclusion. The level of knowledge, attitude, and practice scores were not satisfactory. Majority of the healthcare professionals did not access biomedical waste management training. Educational level, use of visual aid, and availability of color-coded bins in the department were identified as a factor for biomedical waste management. Regular training should be given to healthcare professionals.
\end{abstract}

\section{Background}

During the healthcare delivery process, healthcare establishments can inevitably generate hazardous biomedical wastes (BMWs) to a human being or the environment [1]. These wastes are broadly categorized as general (nonhazardous) and hazardous waste. General waste is constituted $85 \%$ of the total waste while the remaining $15 \%$ is a hazardous waste [2]. There are currently several terms used to describe wastes generated from the healthcare establishments such as clinical waste, healthcare waste, infectious waste, medical waste and biomedical waste are typically encountered [3]. However, BMW is the most frequently used term in most articles. So, in this study, we used this term to represent wastes originated from the healthcare facilities (HCFs). Biomedical waste is generated during diagnosis, treatment or immunization of human beings which mainly includes syringes, needles, ampoules, dressing materials, 
disposable plastics, and microbiological wastes [4]. The main sources of BMWs are hospitals and primary healthcare facilities [5].

The appropriate biomedical waste management (BMWM) process includes vital steps (segregation, storage, transportation, treatment, and disposal) $[6,7]$ which requires special attention [2, 8-10]. The World Health Organization has prepared a BMWM guideline to ensure safe management of the wastes from the HCFs [2]. In addition, there are three main BMWM guidelines in Ethiopia [9-11]. According to these guidelines, as a minimum option, HCFs are required to segregate (separate) BMWs using three types of color-coded bins (black, yellow, and safety box) [9-11].

Generation and disposal of BMWs have become an emerging problem worldwide [8]. It has become a major cause of concern for HCFs and the environment $[12,13]$. According to the World Health Organization report, 10$25 \%$ of the BMW was estimated to be hazardous [2]. However, evidence from different kinds of literatures indicated that the proportion of hazardous waste is varied from country to country ranging from $20 \%$ to $75 \%$ including Ethiopia [14-21]. Biomedical waste management is still at the infancy stage and recently got attention [22] due to increased awareness about human immunodeficiency virus, hepatitis $B$ virus, hepatitis $C$ virus, and other potentially infectious diseases [23]. Biomedical wastes can transmit more than 30 dangerous bloodborne pathogens [24].

A systematic review of 150 articles published since 2000 revealed that at least $50 \%$ of the world population is threatened by public health risks due to mismanagement of BMWs [25]. This is because any carelessness of BMWM can spread infections and contaminate the entire environment [13]. All individuals, particularly healthcare professionals (HCPs), who are on the first line of contact are potentially at risk [26]. Especially, poor BMWM is a problem in most developing countries due to lack of awareness and trained clinical staff in the waste management framework. In addition, the absence of BMWM guideline and suitable treatment and disposal methods could further obstruct the waste management efforts [3]. Currently, BMW disposal in HCFs has become an increasing issue [27] and credible evidence showed that BMWM across Ethiopian health institutions is still inadequate [20]. It was a neglected activity by the healthcare providers and lacked attention it deserves [10].

Biomedical waste management and evaluation studies conducted so far in different parts of Ethiopia reported a high proportion of hazardous BMW generation rates. However, little was reported about the level of knowledge, attitude, practice scores, and associated factors among HCPs who have key roles to ensure effective BMWM. Measuring the level of knowledge, evaluating the attitude, and assessing the practice of healthcare providers and associated factors on BMWM are the key objectives to consider for safe healthcare practice. Therefore, this study is aimed at filling this gap and recommending policymakers to design and implement appropriate intervention to improve safe BMWM in HCFs.

\section{Materials and Methods}

2.1. Study Area and Setting. The study was conducted in Debre Markos town which is located in Amhara regional state at a distance of 300 kilometers from Addis Ababa to the northwest and 265 kilometers from Bahir Dar to the southeast. According to the Ethiopian Central Statistical Agency (CSA) report [28], the town has a population of 119,000 . Among these, $97.1 \%, 1.7 \%$, and $1.1 \%$ were Orthodox Christian, Muslim, and Protestant Christian religion followers, respectively. The three largest ethnic groups in the town were Amhara (97.12\%), Tigrinya (1.29\%), and Oromo (0.67\%) [29]. One referral hospital, 4 health centers, and 12 clinics are found within the town. The hospital has 5 inpatient wards (gynecological, surgical, medical, pediatric, and eye unit) with a total of 400 beds. During 2016/17, the hospital has 35 doctors, 144 nurses, 25 midwives, and 33 laboratory professionals and currently serves 5 million inhabitants in its catchment area [30]. Health centers and clinics have 57 nurses, 24 health officers, 23 laboratory professionals, and 11 midwives, and they currently provide basic health services for the town and nearby areas.

2.2. Study Design and Period. An institution-based crosssectional study was employed from November 2016 to June 2017.

2.3. Sample Size and Sampling Technique. A total of 296 HCPs were studied from 12 HCFs (1 hospital, 4 health centers, and 7 clinics) after excluding those study participants who did not fulfil the eligibility criteria. For this study, an entire population sampling technique (survey) was employed. This sampling technique was used because the number of the study population in the HCFs was small which is manageable for data collection and analysis.

2.4. Eligibility Criteria. All HCPs of the five health professions (medical, laboratory, nurse, health officer, and midwifery) who have at least one year of work experience and permanently employed among Debre Markos town HCFs were studied. Study participants who were available during the data collection period and willing to take part in the study were included. These HCPs were selected because they are mainly involved in the generation, segregation, and management of BMWs than other HCPs. They frequently handle/work with high-risk BMWs who become at risk of occupational health hazards and play a key role to protect the community.

\subsection{Data Collection Tools and Procedure}

2.5.1. Data Collection Tools. Structured self-administered questionnaire and observational checklist were used to collect the data. The questionnaire was developed through a review of the available scientific literatures and national [9-11] and international [2] BMWM guidelines. The questionnaire consisted of four sections (sociodemographic and HCF related factors, knowledge, attitude, and practice). 
2.5.2. Data Collection Procedure. Two trained data collectors (medical laboratory technologist and clinical nurse) were assigned for the data collection process, and the medium of language for data collection was English. Written informed consent containing questionnaires was distributed as hard copy for the study participants. Then data collectors collected completed questionnaires from the study participants, and questionnaires were checked for completeness. Incomplete questionnaires were taken back to the study participants for completion. After completion of the questionnaires, data collectors filled individual observational checklists while the study participants were providing healthcare services. Finally, observational checklists and questionnaires were labeled with HCF and individual identification code numbers and attached together accordingly. After completion of all questionnaires and individual observational checklists, facility observation was conducted using the predetermined structured observational checklist.

2.6. Methods of Measurement (Scoring). All questions of the questionnaire and observational checklist were close-ended. The questionnaire consisted of knowledge, attitude, and practice domains.

(1) Knowledge Domain. This domain consisted of 21 multiple-choice questions and each question had either three or four possible options. Knowledge questions were scored either " 1 " or " 0 for the correct and incorrect response, respectively." The total knowledge score for each study participant was computed, and the possible score could range from 0 to 21 . Then, the overall knowledge score was computed by summation of all the individual study participants' total knowledge scores. Finally, the mean score was calculated by dividing the overall knowledge score by the number of study participants (296). Knowledge scores below and above or equal to the mean score were assigned for inadequate and adequate knowledge, respectively [23, 31].

(2) Attitude Domain. It comprised of 16 Likert items. A fivepoint Likert scale of measurement was used to represent scores, as such "Strongly Disagree," "Disagree," "Neutral," "Agree," and "Strongly Agree" and were given numerical scores 1, 2, 3, 4, and 5, respectively. For negatively phrased statements, scores were reversely coded during the data entry period as $5,4,3,2$, and 1 . Then, the composite score for each study participant was computed which could range from 16 to 80 . The overall attitude score was calculated by adding all the study participants' attitude scores, and the mean score was computed by dividing the overall attitude score by the number of study participants (296). Finally, attitude scores below the mean and above or equal to mean score were assigned for unfavorable and favorable attitude, respectively [31].

(3) Practice Domain. Nine multiple-choice practice questions were used, and they were dichotomized by giving " 1 " or "0" point for correct and incorrect responses, respectively. Likewise, knowledge and attitude questions, for practice questions total individual and overall practice scores were calculated. Then, the mean score was calculated by dividing the overall practice score by the number of study participants (296). Practice scores below the mean and above or equal to the mean score were assigned for inadequate and adequate practice, respectively [31].

2.7. Data Quality Control. Data collection tools were validated with $10 \%$ of the study population who were not included in the final study. According to the pilot survey, the contents of the data collection tools were slightly modified and suggestions from different persons were included. Training was given for data collectors. Timely supervision of data collectors was done by the investigators.

2.8. Data Management and Analysis. Data were entered into Epi-data 3.1 software and then exported to SPSS (Statistical Package for Social Sciences) version 20 for analysis. Descriptive statistics were calculated through cross-tabulation. Bivariate and multivariate logistic regression analyses were computed to identify predictor variables with the statistically significant association. A standard (Enter) method was used for variable selection for the multivariate logistic regression analysis, which means all variables with a $P$ value of $\leq 0.2$ in the bivariate analysis were pooled into the multivariate logistic regression analysis. Variables with a $P$ value of $<0.05$ in the multivariate logistic regression analysis were used to explain the presence of statistically significant associations between the predictor and outcome variables. Finally, Odds Ratio (OR) with $95 \%$ confidence interval (CI) was used to determine the strength of association.

2.9. Ethical Considerations. Ethical approval was obtained from the Departmental Research and Ethics Review Committee (DRERC) of the Department of Medical Laboratory Sciences, Addis Ababa University. Official letters were written from east Gojjam Zonal health department to HCFs, and permission was obtained from the HCFs.

\section{Results}

3.1. Sociodemographic and HCF-Related Characteristics. Two hundred ninety-six study participants were included from 12 HCFs. Among these, 197 (66.6\%), 69 (23.3\%), and $30(10.1 \%)$ were from the hospital, health centers, and clinics, respectively. The mean age of the study participants was $30.46 \pm 6.64$ years. Less than one-third (30.7\%) of the study participants were vaccinated for hepatitis B virus. Regarding previous training, only 109 (36.8\%) had taken BMWM training. One hundred seventy-seven (59.8\%) of the study participants got information from the guideline. Sixty-nine (23.3\%) of the study participants had encountered needlestick/sharps injuries preceding 12 months of the data collection period. Most (97\%) of the HCPs respond the availability of sufficient quantity gloves and $81.4 \%$ of the respondents also disclosed the availability all types 
(black, yellow, and safety box) of color-coded bins in their department (Table 1).

\subsection{Knowledge, Attitude, and Practice of Study Participants}

3.2.1. Knowledge of Study Participants. In this study, HCPs with adequate knowledge score were 168 (56.8\%). One hundred sixty-nine $(57.1 \%)$ of the study participants identified the biohazard symbol. Regarding knowledge on segregation of BMWs, 235 (79.4\%), 217 (73.3\%), and 253 (85.5\%) of the study participants were aware that general, infectious, and sharp wastes should be placed in a black, yellow, and a safety box, respectively. In addition, 254 $(85.8 \%)$ of them were aware that a safety box should be filled only a maximum of 3/4th. Only twenty-nine (9.8\%) of the study participants knew the maximum storage time of infectious wastes before treatment or disposal. Two hundred eighteen $(73.6 \%)$ of them knew 72 hours as a maximum time delay to start HIV postexposure prophylaxis. All doctors were concerned about needlestick injury than other healthcare professionals. About $46 \%$ of health officers did not consider all BMW as hazardous (Table 2).

3.2.2. Attitude of Study Participants. One hundred ninetysix $(66.2 \%)$ of the study participants had favorable attitude score on BMWM. The mean attitude score of Likert items ranged from 3.80 to 4.45 . In addition, 161 (45.9\%) of the study participants strongly agreed to the statement "BMWs should be segregated into different categories at the source" and $191(58.1 \%)$ study participants agreed to the statement "safe BMWM is an issue involving a teamwork." However, to make similar attitude score category with other studies, the five-point Likert scale of measurement was categorized into a three-level Likert scale. Which means strongly disagree and disagree were merged and labeled as disagree; similarly, strongly agree and agree were merged and labeled as agree, whereas neutral remained as it was (Table 3).

3.2.3. Practice of Study Participants. In this study, 229 (77.4\%) of the study participants had adequate practice score and $174(58.8 \%)$ used a visual aid in their department/section. Regarding the use of personal protective equipment, 277 (94\%) and 288 (97\%) of the study participants have always used gloves and gown, respectively, while they were handling BMWs. Two hundred eighty-eight $(79.1 \%)$ of the study participants practiced labeling BMW containers. With respect to segregation of BMWs, 275 (92.9\%) of the study participants segregated BMWs at the source of generation. However, only $261(88.2 \%)$ of them followed color coding segregation. Among these, 228 (77\%), 198 (66.9\%), and 247 (83.4\%) of them put general, infectious, and sharp wastes into the black bin, yellow bin, and safety box, respectively. More specifically, 26 (83.9\%), 140 (85.9\%), $27(100 \%), 45(91.8 \%)$, and $23(88.5 \%)$ doctors, nurses, midwives, laboratory professionals, and health officers, respectively, followed color coding segregation.
TABLE 1: Sociodemographic and HCF-related factors for BMWM at Debre Markos town HCFs, $2017(n=296)$.

\begin{tabular}{|c|c|c|}
\hline $\begin{array}{l}\text { Sociodemographic } \\
\text { and HCF-related } \\
\text { variables }\end{array}$ & $\begin{array}{l}\text { Variable } \\
\text { category }\end{array}$ & $\begin{array}{c}\text { Study } \\
\text { participant, } \\
n(\%) \\
\end{array}$ \\
\hline \multirow{2}{*}{ Gender } & Male & $177(59.8)$ \\
\hline & Female & $119(40.2)$ \\
\hline \multirow{5}{*}{ Age of respondents } & $\leq 25$ years & $44(14.9)$ \\
\hline & $26-30$ years & $159(53.7)$ \\
\hline & $31-35$ years & $42(14.2)$ \\
\hline & $>35$ years & $42(14.2)$ \\
\hline & Missing & $9(3)$ \\
\hline \multirow{3}{*}{ Educational level } & MSc and $\mathrm{MD}^{+}$ & $20(6.8)$ \\
\hline & $\mathrm{BSc}$ & $170(57.4)$ \\
\hline & Diploma & $106(35.8)$ \\
\hline \multirow{5}{*}{ Job category } & Medical doctor & $31(10.5)$ \\
\hline & Nurse & $163(55.1)$ \\
\hline & Midwife & $27(9.1)$ \\
\hline & Laboratory professional & $49(16.6)$ \\
\hline & Health officer & $26(8.8)$ \\
\hline \multirow{5}{*}{$\begin{array}{l}\text { Working } \\
\text { department/section \# }\end{array}$} & OPD & $102(34.5)$ \\
\hline & Ward & $93(31.4)$ \\
\hline & Laboratory room & $48(16.2)$ \\
\hline & Emergency & $64(21.6)$ \\
\hline & Others & $72(24.3)$ \\
\hline \multirow{4}{*}{ Work experience } & $1-5$ years & $143(48.3)$ \\
\hline & $6-10$ years & $98(33.1)$ \\
\hline & $>10$ years & $49(16.6)$ \\
\hline & Missing & $6(2)$ \\
\hline \multirow{4}{*}{ Working hours per day } & $<8$ hours & $6(2)$ \\
\hline & 8 hours & $249(84.1)$ \\
\hline & $>8$ hours & $35(11.8)$ \\
\hline & Missing & $6(2)$ \\
\hline \multirow{3}{*}{$\begin{array}{l}\text { Availability of waste } \\
\text { management guideline }\end{array}$} & Yes & $159(51.6)$ \\
\hline & No & $101(34.1)$ \\
\hline & Not sure & $36(12.2)$ \\
\hline \multirow{3}{*}{$\begin{array}{l}\text { Availability of BMWM } \\
\text { committee in the facility }\end{array}$} & Yes & $188(63.5)$ \\
\hline & No & $57(19.3)$ \\
\hline & Not sure & $51(17.2)$ \\
\hline
\end{tabular}

\# denotes multiple response question; $\mathrm{MD}^{+}$: medical specialists.

3.2.4. Observational Result. Slightly above three-fourths (76\%) of the study participants practiced BMW segregation at the source, and 225 (75\%) of them used biohazard symbollabeled safety boxes for sharp waste segregation. In this study, $70(23.6 \%)$ and $69(23.3 \%)$ of the study participants were working with yellow and black bins containing mixed wastes, respectively. Similarly, one-fourth $(25 \%)$ of the study participants were working with at least one unlabelled BMW containers, and $65(22 \%)$ HCPs were observed using more than 3/4th filled infectious waste containers. Regarding HCF observation, most (91.7\%) of them used puncture-resistant bins to store BMWs temporarily, whereas the other used the incinerator chamber. All HCFs treated BMWs on-site. Among these, $11(91.7 \%)$ used incineration and the remaining used open burning. From the empirical observation, most nongovernmental healthcare facilities' incinerators had remnants of incompletely burned BMWs. Most (91.7\%) of the HCFs disposed of the ash in the placenta pit, latrine opening, or open ground. 
TABle 2: Frequency of study participants among each knowledge item question at Debre Markos town HCFs, 2017 ( $n=296)$.

\begin{tabular}{|c|c|c|c|c|c|}
\hline \multirow[b]{2}{*}{ Variables } & \multicolumn{5}{|c|}{ Job category, $n(\%)$} \\
\hline & $\begin{array}{l}\text { Doctor } \\
(n=31)\end{array}$ & $\begin{array}{c}\text { Nurse } \\
(n=163)\end{array}$ & $\begin{array}{l}\text { Midwife } \\
(n=27)\end{array}$ & $\begin{array}{l}\text { Laboratory } \\
\qquad(n=49)\end{array}$ & $\begin{array}{l}\text { Health officer } \\
\quad(n=26)\end{array}$ \\
\hline Does your facility generate BMWs? & $24(77.4)$ & $129(79.1)$ & $24(88.9)$ & $43(87.8)$ & $24(92.3)$ \\
\hline Do you know about BMWM? & $24(77.4)$ & $113(69.3)$ & $20(74.1)$ & $38(77.6)$ & $24(92.3)$ \\
\hline Is there any health hazard associated with BMWs? & $30(96.8)$ & $148(90.8)$ & $24(88.9)$ & $43(87.8)$ & $24(92.3)$ \\
\hline Is needlestick/sharp injury a concern? & $31(100)$ & $147(90.2)$ & $25(92.6)$ & $43(87.8)$ & $25(96.2)$ \\
\hline Does wearing personal protective equipment reduce the risk of infection? & $29(93.5)$ & $149(91.4)$ & $26(96.3)$ & $47(95.9)$ & $25(96.2)$ \\
\hline Are all BMWs hazardous? & $23(74.2)$ & $99(60.7)$ & $21(77.8)$ & $40(81.6)$ & $14(53.8)$ \\
\hline Are body fluid contaminated items considered as BMWs? & $31(100)$ & $134(82.2)$ & $26(96.3)$ & $45(91.8)$ & $23(88.5)$ \\
\hline Do you know about color coding segregation of BMWs? & $26(83.9)$ & $120(73.6)$ & $21(77.8)$ & $40(81.6)$ & $20(76.9)$ \\
\hline Should infectious waste containers be labeled with a biohazard symbol? & $24(77.4)$ & $126(77.3)$ & $23(85.2)$ & $35(71.4)$ & $25(96.2)$ \\
\hline Should BMWs be segregated at the point of generation? & $25(80.6)$ & $137(84.0)$ & $22(81.5)$ & $40(81.6)$ & $24(92.3)$ \\
\hline Does disinfection of BMWs decrease infection transmission? & $27(87.1)$ & $159(97.5)$ & $27(100)$ & $47(95.9)$ & $26(100)$ \\
\hline Do we need to close BMW containers while transport? & $27(87.1)$ & $127(77.9)$ & $21(77.8)$ & $38(77.6)$ & $24(92.3)$ \\
\hline Do we need to secure BMWs awaiting treatment/disposal? & $26(83.9)$ & $132(81)$ & $24(88.9)$ & $39(79.6)$ & $19(73.1)$ \\
\hline Do you know about BMW disposal methods? & $23(74.2)$ & $98(60.1)$ & $21(77.8)$ & $33(67.3)$ & $22(84.6)$ \\
\hline
\end{tabular}

$n(\%)$ is the proportion of study participants who correctly answered each knowledge question; BMW: biomedical waste; BMWM: biomedical waste management.

TABLe 3: Frequency distribution of study participants among each Likert item of BWM at Debre Markos town HCFs, 2017 ( $n=296$ ).

\begin{tabular}{|c|c|c|c|}
\hline \multirow{2}{*}{ Predictor variables } & \multicolumn{3}{|c|}{ Response options } \\
\hline & Disagree, $n(\%)$ & Neutral, $n(\%)$ & Agree, $n(\%)$ \\
\hline Improperly managed BMWs may cause infection & $37(12.5)$ & $7(2.4)$ & $252(85.1)$ \\
\hline Proper BMW handling is an issue & $34(11.5)$ & $3(1.0)$ & $259(87.5)$ \\
\hline Safe BMWM need a teamwork & $25(8.4)$ & $12(4.1)$ & $259(87.5)$ \\
\hline HIV may be transmitted through BMWs & $27(9.1)$ & $1(.3)$ & $268(90.5)$ \\
\hline HIV postexposure prophylaxis help to prevent the development of HIV infection & $32(10.8)$ & $8(2.7)$ & $256(86.5)$ \\
\hline HBV may be transmitted through BMWs & $14(4.7)$ & $8(2.7)$ & $274(92.6)$ \\
\hline HCV may be transmitted through BMWs & $41(13.9)$ & $34(11.5)$ & $221(74.7)$ \\
\hline BMWs do not transmit any infectious diseases & $24(8.1)$ & $12(4.1)$ & $260(87.8)$ \\
\hline BMWs should be segregated into different categories at the point of generation & $41(13.9)$ & $14(4.7)$ & $241(81.4)$ \\
\hline BMW segregation facilitates safe handling & $40(13.5)$ & $8(2.7)$ & $248(83.8)$ \\
\hline Labelling BMW containers have no significance & $52(17.6)$ & $12(4.1)$ & $232(78.4)$ \\
\hline Proper BMW disposal is important to prevent infection transmission & $23(7.8)$ & $2(.7)$ & $271(91.6)$ \\
\hline BMW disinfection can reduce the chance of contracting the infection & $32(10.8)$ & $10(3.4)$ & $254(85.8)$ \\
\hline Wearing personal protective equipment helps to reduce the risk of infection & $25(8.4)$ & $5(1.7)$ & $266(89.9)$ \\
\hline BMWM add extra burden of work & $83(28.0)$ & $21(7.1)$ & $192(64.9)$ \\
\hline Biohazardous wastes should be disinfected before disposal & $59(19.9)$ & $21(7.1)$ & $216(73.0)$ \\
\hline
\end{tabular}

\subsection{Associated Factors}

3.3.1. Factors Associated with Knowledge. In the bivariate analysis, age group, job category, and information sourced from the guideline were marginal, whereas educational level, presence of BMWM committee, working experience, previous training, presence of BMWM guideline, attitude, and practice scores of study participants showed a statistically significant association with the knowledge score. After adjustment of possible confounds, however, MSc and $\mathrm{MD}^{+}$ (AOR: 14, 95\% CI: $(1.37,149.52)$ ), working in another department (AOR: 2.22, 95\% CI: $(1.03,4.77)$ ), attitude score (AOR: $2.09,95 \%$ CI: $(1.09,4.00)$ ), and practice score (AOR: $2.28,95 \%$ CI: $(1.18,4.42))$ of the study participants were more likely to contribute for adequate knowledge score compared with the respective reference groups given that other predictor variables were held constant (Table 4).
3.3.2. Factors Associated with Attitude. In the bivariate analysis, sex, and type of HCF were marginal, whereas information source from the guideline, educational level, previous training, and knowledge scores of the study participants showed a statistically significant association with the attitude score. After adjustment of possible confounds, however, information source from guideline (AOR: 1.82, 95\% CI: $(1.07,3.10)$ ) and BSc holders (AOR: 2.53, 95\% CI: $(1.47,4.38))$ was more likely to be contributed for favorable attitude score compared with the reference groups given that other predictor variables were held constant (Table 5).

3.3.3. Factors Associated with Practice. In the bivariate analysis, working department and job category of study participants were marginal, whereas the presence of guideline, educational level, previous training, use of visual 
TABLE 4: Bivariate and multivariate logistic regression analysis of factors against knowledge scores of study participants at Debre Markos town HCFs, $2017(n=296)$.

\begin{tabular}{|c|c|c|c|c|c|c|c|c|}
\hline \multirow{2}{*}{\multicolumn{2}{|c|}{ Variables }} & & \multicolumn{2}{|c|}{ Knowledge } & \multirow{2}{*}{ COR $(95 \%$ CI $)$} & \multirow{2}{*}{$P$ value } & \multirow{2}{*}{$\begin{array}{c}\text { AOR } \\
(95 \% \mathrm{CI})\end{array}$} & \multirow{2}{*}{$P$ value } \\
\hline & & & $\mathrm{IK}(n)$ & $\mathrm{AK}(n)$ & & & & \\
\hline \multirow{4}{*}{\multicolumn{2}{|c|}{ Age group }} & $\leq 25$ years & 17 & 27 & $0.433(0.17,1.13)$ & 0.086 & & \\
\hline & & $26-30$ & 48 & 111 & $0.63(0.28,1.42)$ & 0.265 & & \\
\hline & & $31-35$ & 9 & 33 & $1.0(0.35,2.84)$ & 1.00 & & \\
\hline & & $\geq 36$ years & 9 & 33 & 1 & & & \\
\hline \multirow{5}{*}{\multicolumn{2}{|c|}{ Job category }} & Doctor & 8 & 23 & $0.69(0.19,2.42)$ & 0.557 & & \\
\hline & & Nurse & 57 & 106 & $0.44(0.16,1.24)$ & 0.120 & & \\
\hline & & Midwife & 7 & 20 & $0.68(0.19,2.50)$ & 0.562 & & \\
\hline & & Laboratory & 10 & 39 & $0.93(0.28,3.08)$ & 0.903 & & \\
\hline & & Health officer & 5 & 21 & 1 & & & \\
\hline \multirow{3}{*}{\multicolumn{2}{|c|}{ Educational level }} & MSc and $\mathrm{MD}^{+}$ & 1 & 19 & $7.85(1.01,61.25)$ & $0.049^{*}$ & $4(1.37,149.52)$ & $0.023^{*}$ \\
\hline & & $\mathrm{BSc}$ & 55 & 115 & $0.86(0.51,1.47)$ & 0.588 & & \\
\hline & & Diploma & 31 & 75 & 1 & & 1 & \\
\hline \multirow{6}{*}{ Department } & \multirow{2}{*}{ Ward } & Yes & 32 & 61 & $0.71(0.42,1.20)$ & 0.201 & & \\
\hline & & No & 55 & 148 & 1 & & & \\
\hline & \multirow{2}{*}{ Laboratory } & Yes & 9 & 39 & $1.99(0.92,4.31)$ & 0.081 & & \\
\hline & & No & 78 & 170 & 1 & & & \\
\hline & \multirow{2}{*}{ Others } & Yes & 26 & 46 & $0.66(0.38,1.16)$ & 0.152 & $2.22(1.03,4.77)$ & $0.042^{*}$ \\
\hline & & No & 61 & 163 & 1 & & 1 & \\
\hline \multirow{3}{*}{\multicolumn{2}{|c|}{ Work experience }} & $1-5$ years & 52 & 91 & 1 & & & \\
\hline & & $6-10$ years & 23 & 75 & $1.86(1.05,3.32)$ & $0.035^{*}$ & & \\
\hline & & $>10$ years & 10 & 39 & $2.23(1.03,4.83)$ & $0.042^{*}$ & & \\
\hline \multirow{6}{*}{$\begin{array}{l}\text { Information } \\
\text { source }\end{array}$} & \multirow{2}{*}{ Guideline } & Yes & 45 & 132 & $1.60(0.97,2.65)$ & 0.069 & & \\
\hline & & No & 42 & 77 & 1 & & & \\
\hline & \multirow{2}{*}{ Training } & Yes & 28 & 114 & $2.53(1.50,4.28)$ & $0.001^{*}$ & & \\
\hline & & No & 59 & 95 & 1 & & & \\
\hline & \multirow{2}{*}{ Others } & Yes & 29 & 36 & $0.42(0.24,0.74)$ & $0.003^{*}$ & & \\
\hline & & No & 58 & 173 & 1 & & & \\
\hline \multirow{2}{*}{\multicolumn{2}{|c|}{ Previous training }} & Yes & 20 & 89 & $2.49(1.41,4.39)$ & $0.002^{*}$ & & \\
\hline & & No & 67 & 120 & 1 & & & \\
\hline \multirow{2}{*}{\multicolumn{2}{|c|}{$\begin{array}{l}\text { Presence of BMWM } \\
\text { committee in the facility }\end{array}$}} & Yes & 45 & 143 & $2.02(1.21,3.37)$ & $0.007^{*}$ & & \\
\hline & & No and not sure & 42 & 66 & 1 & & & \\
\hline \multirow{2}{*}{\multicolumn{2}{|c|}{ Presence of guideline }} & Yes & 32 & 127 & $2.66(1.59,4.46)$ & $0.001^{*}$ & & \\
\hline & & No and not sure & 55 & 82 & 1 & & & \\
\hline \multirow{2}{*}{\multicolumn{2}{|c|}{ Attitude score }} & Unfavorable & 38 & 62 & 1 & & 1 & \\
\hline & & Favorable & 49 & 147 & $1.84(1.10,3.08)$ & $0.021^{*}$ & $2.09(1.09,4.00)$ & $0.026^{*}$ \\
\hline \multirow{2}{*}{\multicolumn{2}{|c|}{ Practice score }} & Inadequate & 41 & 66 & 1 & & 1 & \\
\hline & & Adequate & 46 & 143 & $1.93(1.16,3.22)$ & $0.012^{*}$ & $2.28(1.18,4.42)$ & $0.014^{*}$ \\
\hline
\end{tabular}

AK: adequate knowledge; IK: inadequate knowledge; $\mathrm{MD}^{+}$: medical specialists; $\mathrm{MSc}$ : master of science; BSc: bachelor of science; COR: crude odds ratio; AOR: adjusted odds ratio; CI: confidence interval; * statistically significant at $P$ value $<0.05$.

aid, and presence of color-coded bins in the department showed a statistically significant association. After adjustment of possible confounds, use of visual aid and availability of all the three types of color-coded bins in the department (AOR: 5.34, 95\% CI: (2.87, 9.95), and AOR: 7.68, 95\% CI: $(3.30,17.89)$, respectively) were more likely to contribute to adequate BMWM practice given that other predictor variables were constant (Table 6).

\section{Discussion}

Healthcare facilities have a responsibility to protect the environment and public health. Thus, providing training for HCPs for effective BMWM is a very critical step. However, in this study, only $36.8 \%$ of the study participants were trained on BMWM which is lower than $61.6 \%$ and $46.9 \%$ studies conducted in Bangladesh and Gondar town, respectively $[32,33]$. This result was, however, more or less similar to a study conducted in Adama, Ethiopia 31\% [16].

Regarding incidence of needlestick/sharp injuries, about $23.3 \%$ cases occurred during the previous 12 months preceding the data collection time, which is better than $51 \%$ and $30.8 \%$ studies conducted in Nigeria and Gondar town, respectively $[34,35]$. However, a similar study (25\%) was found in Gondar town with a different time period [35].

According to the World Health Organization and Ethiopian Food, Medicine and Healthcare Administration 
TABLE 5: Bivariate and multivariate logistic regression analysis of factors against attitude scores of study participants at Debre Markos town HCFs, $2017(n=296)$.

\begin{tabular}{|c|c|c|c|c|c|c|c|}
\hline \multirow{2}{*}{ Variables } & & \multicolumn{2}{|c|}{ Attitude } & \multirow{2}{*}{ COR $(95 \%$ CI $)$} & \multirow{2}{*}{$P$ value } & \multirow{2}{*}{ AOR (95\% CI) } & \multirow{2}{*}{$P$ value } \\
\hline & & $\mathrm{UA}(n)$ & FA $(n)$ & & & & \\
\hline \multirow{2}{*}{ Sex } & Male & 52 & 125 & $1.63(.10,2.65)$ & 0.051 & & \\
\hline & Female & 48 & 71 & 1 & & & \\
\hline \multirow{2}{*}{$\begin{array}{l}\text { Information source } \\
\text { from guideline }\end{array}$} & Yes & 48 & 129 & $2.09(1.28,3.41)$ & $0.003^{*}$ & $1.82(1.07,3.10)$ & $0.028^{*}$ \\
\hline & No & 52 & 67 & 1 & & 1 & \\
\hline \multirow{3}{*}{ Educational level } & MSc and $\mathrm{MD}^{+}$ & 4 & 16 & $3.85(1.21,12.29)$ & $0.023^{*}$ & & \\
\hline & $\mathrm{BSc}$ & 44 & 126 & $2.76(1.65,4.60)$ & $0.001^{*}$ & $2.53(1.47,4.38)$ & $0.001^{*}$ \\
\hline & Diploma & 52 & 54 & 1 & & 1 & \\
\hline \multirow{3}{*}{ Type of facility } & Hospital & 57 & 140 & $1.64(0.74,3.62)$ & 0.200 & & \\
\hline & Health center & 31 & 38 & $0.82(0.34,1.95)$ & 0.650 & & \\
\hline & Clinic & 12 & 18 & 1 & & & \\
\hline \multirow{2}{*}{ Training } & Yes & 27 & 82 & $1.2(0.32, .86)$ & $0.010^{*}$ & $1.4(0.26,0.80)$ & $0.006^{*}$ \\
\hline & No & 53 & 134 & 1 & & 1 & \\
\hline \multirow{2}{*}{ Knowledge score } & Inadequate & 38 & 49 & $0.54(0.32,0.91)$ & $0.021^{*}$ & $0.44(0.25,0.78)$ & $0.005^{*}$ \\
\hline & Adequate & 62 & 147 & 1 & & 1 & \\
\hline
\end{tabular}

FA: favorable attitude; UA: unfavorable attitude; $\mathrm{MD}^{+}$: medical specialists: MSc: master of science; BSc; bachelor of science; COR: crude odds ratio; AOR: adjusted odds ratio; CI: confidence interval; ${ }^{*}$ statistically significant at a $P$ value of $<0.05$.

TABLE 6: Bivariate and multivariate logistic regression analysis of factors against practice scores of study participants at Debre Markos town HCFs, 2017.

\begin{tabular}{|c|c|c|c|c|c|c|c|c|}
\hline \multirow{2}{*}{ Variables } & & & \multicolumn{2}{|c|}{ Practice } & \multirow{2}{*}{ COR (95\% CI) } & \multirow{2}{*}{$P$ value } & \multirow{2}{*}{ AOR (95\% CI) } & \multirow{2}{*}{$P$ value } \\
\hline & & & $\mathrm{IP}(n)$ & $\operatorname{AP}(n)$ & & & & \\
\hline \multirow{6}{*}{$\begin{array}{l}\text { Working } \\
\text { department }\end{array}$} & \multirow{2}{*}{ OPD } & Yes & 44 & 58 & $0.63(0.39,1.04)$ & 0.070 & & \\
\hline & & No & 63 & 131 & 1 & & & \\
\hline & \multirow{2}{*}{ Ward } & Yes & 28 & 65 & $1.48(0.88,2.50)$ & 0.144 & & \\
\hline & & No & 79 & 124 & 1 & & & \\
\hline & \multirow{2}{*}{ Laboratory } & Yes & 22 & 26 & $1.48(0.88,2.50)$ & 0.144 & & \\
\hline & & No & 85 & 163 & 1 & & & \\
\hline \multirow{6}{*}{$\begin{array}{l}\text { Information } \\
\text { source from }\end{array}$} & \multirow{2}{*}{ Guideline } & Yes & 58 & 119 & $1.44(0.89,2.32)$ & 0.141 & & \\
\hline & & No & 49 & 70 & 1 & & & \\
\hline & \multirow{2}{*}{ Training } & Yes & 41 & 101 & $1.85(0.14,3.0)$ & $0.013^{*}$ & & \\
\hline & & No & 66 & 88 & 1 & & & \\
\hline & \multirow{2}{*}{ Others } & Yes & 31 & 34 & $0.54\left(\begin{array}{lll}0.31 & 0.94\end{array}\right)$ & $0.030^{*}$ & & \\
\hline & & No & 76 & 155 & 1 & & & \\
\hline \multirow{3}{*}{\multicolumn{2}{|c|}{ Educational level }} & $\mathrm{MSc}$ and $\mathrm{MD}^{+}$ & 6 & 14 & $0.92(0.32,2.62)$ & 0.877 & & \\
\hline & & $\mathrm{BSc}$ & 71 & 99 & $0.55(0.33,0.93)$ & $0.025^{*}$ & & \\
\hline & & Diploma & 30 & 76 & 1 & & & \\
\hline \multirow{5}{*}{\multicolumn{2}{|c|}{ Job category }} & Doctor & 16 & 15 & $0.50(0.17,1.45)$ & 0.20 & & \\
\hline & & Nurse & 50 & 113 & $1.2(0.50,2.87)$ & 0.687 & & \\
\hline & & Midwife & 9 & 18 & $1.10(0.34,3.30)$ & 0.922 & & \\
\hline & & Laboratory & 23 & 26 & $0.60(0.22,1.60)$ & 0.306 & & \\
\hline & & Health officer & 9 & 17 & 1 & & & \\
\hline \multirow{2}{*}{\multicolumn{2}{|c|}{ Previous training }} & Yes & 28 & 81 & $2.12(1.26,3.55)$ & $0.005^{*}$ & & \\
\hline & & No & 79 & 108 & 1 & & & \\
\hline \multirow{2}{*}{\multicolumn{2}{|c|}{ Use of visual aid }} & Yes & 35 & 139 & $5.72(3.419 .59)$ & $0.001^{*}$ & $5.34(2.87,9.95)$ & $0.001^{*}$ \\
\hline & & No & 72 & 50 & 1 & & 1 & \\
\hline \multirow{2}{*}{\multicolumn{2}{|c|}{$\begin{array}{l}\text { Presence of BMWM } \\
\text { committee }\end{array}$}} & Yes & 55 & 133 & $2.25(1.37,3.67)$ & $0.001^{*}$ & & \\
\hline & & No & 52 & 56 & 1 & & & \\
\hline \multirow{2}{*}{\multicolumn{2}{|c|}{ Availability of guideline }} & Yes & 44 & 115 & $2.23(1.37,3.61)$ & $0.001^{*}$ & & \\
\hline & & No & 63 & 74 & 1 & & & \\
\hline \multirow{2}{*}{\multicolumn{2}{|c|}{$\begin{array}{l}\text { Availability of color-coded } \\
\text { bins }\end{array}$}} & Yes & 64 & 177 & $9.91(4.92,20.0)$ & $0.001^{*}$ & $7.68(3.30,17.89)$ & $0.001^{*}$ \\
\hline & & No & 43 & 12 & 1 & & 1 & \\
\hline \multicolumn{2}{|c|}{ Knowledge group } & Inadequate & 41 & 46 & $0.52(0.31,0.86)$ & $0.012^{*}$ & & \\
\hline
\end{tabular}

AP: adequate practice; IP: inadequate practice; OPD: outpatient department; $\mathrm{MD}^{+}$: medical specialists; MSc: master of science; $\mathrm{BSc}$ : bachelor of science; $\mathrm{COR}$ : crude odds ratio; AOR: adjusted odds ratio; CI: confidence interval; * statistically significant at $P$ value $<0.05$. 
and Control Authority BMWM guidelines, to prevent occupational health risks, healthcare workers should be protected by hepatitis B virus vaccination $[2,9]$. However, in this study, hepatitis B virus vaccination was low (30.7\%) as the level of occupational exposure among HCPs is high. It is extremely low compared to $85.8 \%$ and $95 \%$ studies conducted in India and Iran, respectively $[13,36]$. Unavailability and cost of the vaccine could be the possible causes for low vaccination status of HCPs in the current study.

4.1. Knowledge of Study Participants. Adequate knowledge is vital for appropriate BMWM practice. However, in this study, only $56.8 \%$ of the study participants had adequate knowledge score, which is better than $45 \%$ and $40.5 \%$ studies conducted in Nigeria and Sri Lanka, respectively [37, 38]. A better result was found in Pakistan where $96 \%$ of the study participants had good knowledge score [39].

This could be due to the difference in availability and utilization of waste management guidelines among the facilities, providing training opportunity for HCPs, national health sector strategy difference, or it might be due to academic performance difference of study participants. As a minimum standard, a three-bin system of BMW segregation has been established in Ethiopia [9, 10]. However; only $77.2 \%$ of the study participants had knowledge of color coding segregation which is lower than $92.3 \%$ of a report from India [31]. About 72.6\%, 78.3\%, and 86.3\% study participants were able to identify that general, infectious, and sharp wastes should be placed in black, yellow, and a safety box, respectively. According to guidelines, infectious waste containers should be labeled with a biohazard symbol [2, 9-11]. However, only half (53.6\%) of study participants were able to identify the biohazard symbol which is similar to a study in India (54.4\%) [40]. However, a better result was found in Nainital city in India where the majority of HCWs $(85.5 \%)$ were able to identify a symbol of biohazards [23].

4.2. Attitude of Study Participants. The overall favorable attitude score of HCPs was $62.1 \%$ which is more or less comparable with $59.9 \%$ in a study conducted at Gondar town [41]. Similarly, the majority of study participants in Sri Lanka and almost all studied participants in the Tripura state of India had favorable attitude $[31,38]$. However, this study was better than a study from Nigeria [37]. This could be due to methodological difference or commitment of healthcare staff for waste management. With regard to waste segregation and treatment, about $86.3 \%$ and $74.6 \%$ study participants agreed that BMWs should be segregated at the source and disinfected before disposal, respectively. A similar study was found in India in which about $88.1 \%$ study participants agreed on segregation of BMWs at the source [31].

4.3. Practice of Study Participants. Adequate practice score of the study participants was $78.9 \%$, which is better than $31.5 \%$ and $74.8 \%$ in studies conducted in Ethiopia and Sri Lanka $[33,38]$, respectively. However, a better result was found from Pakistan where $94.3 \%$ of the study participants had adequate practice [39]. This could be due to lack of training, HCPs commitment, motivation, and enforcement from concerned bodies or ignorance of HCPs for BMWM. The highest practice score was noted among midwives (92.6\%); however, the list was disappointingly among medical doctors (58.1\%). One could ask if over qualification leads to ignorance. However, it is more or less comparable to a study from Bangladesh, where $44 \%$ of medical doctors studied had adequate practice [42]. Similarly, a study conducted in India indicated that the highest adequate practice score was among Nurses (97.3\%) followed by doctors (77.8) [43]. Probably this difference could be due to the accessibility of BMWM equipment, training opportunity, and guidelines. Biomedical waste segregation is the most critical step for proper waste management, and it should be done at the point of generation using color-coded bins [2]. All hazardous wastes should be segregated at the point of generation [2,9-11]; however, in this study, only $88.2 \%$ of HCPs were segregated at the source at the source of generation.

4.4. Treatment and Disposal. Most studied HCFs (91.7\%) used puncture-resistant containers for BMW storage until treatment or disposal, and the remaining used the incinerator chamber as a temporary waste storage means. These practices are not in line with the national guideline requirement where all HCFs should have separate waste storage facilities for hazardous BMWs [10]. In most HCFs, waste treatment was done according to the volume of waste collected rather than the time of storage [10]. Two HCFs (16.7\%) burn all types of BMWs in an unprotected environment. Most HCFs (91.7\%) did not have specifically designed ash pit, and they dispose of either in placenta pit, latrine opening, or open dumping. These are bad activities which are strongly prohibited and are out of the guidelines recommendation $[2,9,10]$.

4.5. Limitations of the Study. In this study, liquid BMWs were not assessed due to financial constraint. Since the study was conducted in a limited geographical area, it could not be generalized at a national level. Similarly, BMW generation rates among studied facilities were not measured due to financial constraint. Healthcare facility observation was conducted at one point in time, which may have an implication of the study.

\section{Conclusion and Recommendation}

In this study, HCPs level of knowledge, attitude, and practice scores is low. The majority of the studied HCPs did not access BMWM training. Similarly, about half of them did not access BMWM guidelines in their department. Educational level, use of visual aid, and availability of all the three types of color-coded bins in the department/working section were identified as a key factor for effective BMWM. Regular waste management training should be given for HCPs, and they should have access to BMWM guidelines in their department/healthcare delivery section. In addition, periodic and comprehensive studies should be conducted. 


$\begin{array}{ll}\text { Abbreviations } \\ \text { BSc: } & \text { Bachelor of sciences } \\ \text { HCFs: } & \text { Healthcare facilities } \\ \text { HCPs: } & \text { Healthcare professionals } \\ \text { BMW: } & \text { Biomedical waste } \\ \text { BMWM: } & \text { Biomedical waste management } \\ \text { OPD: } & \text { Outpatient department } \\ \text { MSc: } & \text { Masters of sciences } \\ \text { COR: } & \text { Crude odds ratio } \\ \text { AOR: } & \text { Adjusted odds ratio } \\ \text { CI: } & \text { Confidence interval } \\ \text { AK: } & \text { Adequate knowledge } \\ \text { IK: } & \text { Inadequate knowledge } \\ \text { FA: } & \text { Favorable attitude } \\ \text { UA: } & \text { Unfavorable attitude } \\ \text { AP: } & \text { Adequate practice } \\ \text { IP: } & \text { Inadequate practice. }\end{array}$

\section{Data Availability}

The data used to support the findings of this study are available from the corresponding author upon request.

\section{Conflicts of Interest}

The authors declare that there are no conflicts of interest regarding the publication of this paper.

\section{Authors' Contributions}

Teshiwal Deress participated in idea conception, proposal development, data collection supervision, writing the manuscript, and communicating the manuscript. Fatuma Hassen participated in proposal development, data collection, and writing the manuscript. Kasaw Adane participated in data collection and writing the manuscript. Aster Tsegaye participated in idea conception, proposal development, data collection, and writing the manuscript.

\section{Acknowledgments}

The authors would like to thank Addis Ababa University, East Gojjam Zone health department, and Debre Markos town district health office for their contribution to this study. In addition, the authors would also like to extend their appreciation to all the study participants, data collectors, health facilities, and authors whose materials were used for the development of this article. This study was fully funded by Addis Ababa University.

\section{Supplementary Materials}

Questionnaire and observational checklist. (Supplementary Materials)

\section{References}

[1] V. N. Pinto, S. M. Joshi, D. H. Velankar, M. J. Mankar, H. Bakshi, and A. Nalgundwar, "A comparative study of knowledge and attitudes regarding biomedical waste (BMW) management with a preliminary intervention in an academic hospital," International Journal of Medicine and Public Health, vol. 4, no. 1, pp. 91-95, 2014.

[2] Y. Chartier, J. Emmanuel, U. Pieper, A. Prüss, P. Rushbrook, and R. Stringer, Safe Management of Wastes from Healthcare Activities, World Health Organization (WHO), Geneva, Switzerland, 2nd edition, 2014.

[3] M. S. Hossain, A. Santhanam, N. N. Norulaini, and A. M. Omar, "Clinical solid waste management practices and its impact on human health and environment-a review," Waste Management, vol. 31, no. 4, pp. 754-766, 2011.

[4] E. O. Ola-Adisa, Y. E. Mangden, Y. C. Sati, and J. O. Adisa, "Knowledge, attitudes/beliefs and practices in medical waste management-an appraisal of Jos North LGA, Plateau State, Nigeria," International Journal, vol. 2, pp. 43-56, 2015.

[5] Z. Bendjoudi, F. Taleb, F. Abdelmalek, and A. Addou, "Healthcare waste management in Algeria and Mostaganem department," Waste Management, vol. 29, no. 4, pp. 13831387, 2009.

[6] M. D. Asadullah, G. K. Karthik, and B. Dharmappa, "A study on knowledge, attitude and practices regarding biomedical waste management among nursing staff in private hospitals in Udupi city, Karnataka, India," International Journal of Geology, Earth and Environmental Sciences, vol. 3, no. 1, pp. 118-123, 2013.

[7] A. Singh, R. Kumari, A. Wakhlu, K. Srivastava, A. Wakhlu, and S. Kumar, "Assessment of biomedical waste management in a government healthcare setting of North India," International Journal of Health Sciences and Research, vol. 4, no. 11, pp. 203-208, 2014.

[8] S. Chakraborty, B. Veeregowda, L. Gowda et al., "Biomedical waste management," Advances in Animal and Veterinary Sciences, vol. 2, no. 2, pp. 67-72, 2014.

[9] Food, Medicine and Healthcare Administration and Control Authority (FMHACA), Healthcare Waste Management Directive, FMHACA, Addis Ababa, Ethiopia, 2005.

[10] Federal Ministry of Health (FMoH), Healthcare Waste Management National Guidelines, Hygiene and Environmental Health Development, FMoH, Addis Ababa, Ethiopia, 2008.

[11] Federal Environmental Protection Authority (FEPA), Technical Guidelines on the Environmentally Sound Management of Biomedical and Healthcare Wastes, FEPA, Addis Ababa Ethiopia, 2004.

[12] R. Chudasama, M. Rangoonwala, A. Sheth, S. K. Misra, A. M. Kadri, and U. V. Patel, "Biomedical waste management: a study of knowledge, attitude and practice among healthcare personnel at tertiary care hospital in Rajkot," Journal of Research in Medical and Dental Science, vol. 1, no. 1, pp. 17-22, 2017.

[13] V. Mane, S. M. Nimbannavar, and B. Y. Yuvaraj, "Knowledge, attitude and practices on biomedical waste and its management among healthcare workers at a tertiary care hospital in Koppal, Karnataka, India," International Journal of Community Medicine and Public Health, vol. 3, no. 10, pp. 2953-2957, 2016.

[14] B. E. Bassey, M. O. Benka-Coker, and H. S. Aluyi, "Characterization and management of solid medical wastes in the federal capital territory, Abuja Nigeria," African Health Sciences, vol. 6, no. 1, pp. 59-63, 2006.

[15] S. K. Sarkar, M. A. Haque, and T. A. Khan, "Hospital waste management in Sylhet city," ARPN Journal of Engineering and Applied Sciences, vol. 1, no. 2, pp. 32-40, 2006. 
[16] S. F. Hayleeyesus and W. Cherinete, "Healthcare waste generation and management in public healthcare facilities in Adama, Ethiopia," Journal of Health and Pollution, vol. 6, no. 10, pp. 64-73, 2016.

[17] I. D. Haylamicheal, M. A. Dalvie, B. D. Yirsaw, and H. A. Zegeye, "Assessing the management of healthcare waste in Hawassa city, Ethiopia," Waste Management and Research, vol. 29 , no. 8, pp. 854-862, 2011.

[18] E. Tesfahun, A. Kumie, W. Legesse, H. Kloos, and A. Beyene, "Assessment of composition and generation rate of healthcare wastes in selected public and private hospitals of Ethiopia," Waste Management and Research, vol. 32, no. 3, pp. 215-220, 2014.

[19] D. Debalkie and A. Kumie, "Healthcare waste management: the current issues in Menellik II hospital, Ethiopia," Current World Environment, vol. 12, no. 1, pp. 42-52, 2017.

[20] M. Azage and A. Kumie, "Healthcare waste generation and its management system: the case of health centers in West Gojjam Zone, Amhara region," Ethiopia. Ethiopian Journal of Health Development, vol. 24, no. 2, pp. 119-126, 2010.

[21] M. L. Tadesse and A. Kumie, "Healthcare waste generation and management practice in government health centers of Addis Ababa, Ethiopia," Biomed Central Public Health, vol. 14, p. 1221, 2014.

[22] B. R. Babu, A. K. Parande, R. Rajalakshmi, P. Suriyakala, and M. Volga, "Management of biomedical waste in India and other countries: a review," Journal of International Environmental Application and Science, vol. 4, pp. 65-78, 2009.

[23] M. Kumar, R. K. Singh, and V. R. Umesh, "Awareness and practices about biomedical waste among healthcare workers in tertiary care hospital of Haldwani, Nainital," National Journal of Medical Research, vol. 159, pp. 72-73, 2015.

[24] M. Sawalem, E. Selic, and J. D. Herbell, "Hospital waste management in Libya: a case study," Waste Management, vol. 29, no. 4, pp. 1370-1375, 2009.

[25] M. Caniato, T. Tudor, and M. Vaccari, "International governance structures for healthcare waste management: A systematic review of scientific literature," Journal of Environmental Management, vol. 153, pp. 93-107, 2015.

[26] N. Marinković, K. Vitale, N. J. Holcer, A. Džakula, and T. Pavic, "Management of hazardous medical waste in Croatia," Waste Management, vol. 28, no. 6, pp. 1049-1056, 2008.

[27] P. Mathur, S. Patan, and S. Shobhawat, "Need of biomedical waste management system in hospitals-an emerging issue-a review," Current World Environment, vol. 7, no. 1, pp. 117-124, 2012.

[28] Central Statistical Authority (CSA), National Statistics Abstract, CSA, Addis Ababa, Ethiopia, 2010.

[29] D. Emebet, K. Awoke, and A. Asenakew, "Challenges, opportunities and management practice of pig production in Debre Markos Town, East Gojjam Zone in Amahara Regional State, Ethiopia," Poultry, Fisheries and Wildlife Sciences, vol. 5, p. 176, 2017.

[30] F. A. Teshager, E. H. Engeda, and W. Z. Worku, "Knowledge, practice, and associated factors towards prevention of surgical site infection among nurses working in Amhara regional state referral hospitals, northwest Ethiopia," Surgery Research and Practice, vol. 2015, Article ID 736175, 6 pages, 2015.

[31] N. Karmakar, S. S. Datta, A. Datta, K. Nag, K. Tripura, and P. Bhattacharjee, "A cross-sectional study on knowledge, attitude and practice of biomedical waste management by healthcare personnel in a tertiary care hospital of Agartala, Tripura," National Journal of Research in Community Medicine, vol. 5, no. 3, 2016.
[32] M. N. Uddin, M. R. Islam, and K. Yesmin, "Knowledge on hospital waste management among senior staffnurses working in a selected medical college hospital of Bangladesh," Journal of Waste Management, vol. 2014, Article ID 573069, 5 pages, 2014.

[33] M. Azage, G. Haimanot, and M. Mesafint, "Healthcare waste management practices among healthcare workers in healthcare facilities of Gondar town, northwest Ethiopia," Health Science Journal, vol. 7, pp. 15-26, 2013.

[34] A. R. Isara, K. E. Oguzie, and O. E. Okpogoro, "Prevalence of needle stick injuries among healthcare workers in the accident and emergency department of a teaching hospital in Nigeria," Annals of Medical and Health Sciences Research, vol. 5, no. 6, pp. 392-396, 2015.

[35] G. Kebede, M. Molla, and H. R. Sharma, "Needle stick and sharps injuries among healthcare workers in Gondar city, Ethiopia," Safety Science, vol. 50, no. 4, pp. 1093-1097, 2012.

[36] A. Amouei, S. H. Fallah, H. A. Asgharnia, M. Gholami, and S. Jafarian, "Knowledge and attitude of hospital personnel regarding medical waste management," International Archives of Health Sciences, vol. 2, pp. 75-81, 2015.

[37] A. Sabageh, A. Adeomi, O. Adediran, O. Abodunrin, O. Oladimeji, and F. Eunice, "Perception and practices of healthcare workers in south-western Nigeria towards healthcare waste management," British Journal of Medical and Health Research, vol. 2, pp. 19-26, 2015.

[38] M. A. Samarakoon and N. S. Gunawardena, "An evaluation of healthcare waste management in base hospitals of Colombo district," Journal of the College of Community Physicians of Sri Lanka, vol. 16, no. 2, pp. 15-20, 2011.

[39] S. Ajmal and M. Ajmal, "Knowledge and Practices of Biomedical Waste Management among Paramedic Staff of Jinnah Hospital, Lahore," Biologia, vol. 63, pp. 59-66, 2017.

[40] R. Radha, "Assessment of existing knowledge, attitude and practices regarding biomedical waste management among the healthcare workers in a tertiary care rural hospital," International Journal of Health Services and Research, vol. 2, pp. 14-19, 2012.

[41] M. A. Yenesew, H. G. Moges, and S. M. Woldeyohannes, "A cross sectional study on factors associated with risk perception of healthcare workers toward healthcare waste management in healthcare facilities of Gondar town, northwest Ethiopia," International Journal of Infection Control, vol. 8, no. 3, 2012.

[42] M. A. Sarker, M. Harun-Or-Rashid, T. Hirosawa et al., "Evaluation of knowledge, practices, and possible barriers among healthcare providers regarding medical waste management in Dhaka, Bangladesh," Medical Science Monitor: International Medical Journal of Experimental and Clinical Research, vol. 20, pp. 2590-2597, 2014.

[43] R. Ray, T. K. Ghosh, N. N. Hait, R. N. Ray, and S. Mishra, “A study of knowledge attitude and practices of biomedical waste management at a tertiary care hospital, Kolkata," Journal of Medical Science and Clinical Research, vol. 2, pp. 1930-1940, 2014. 


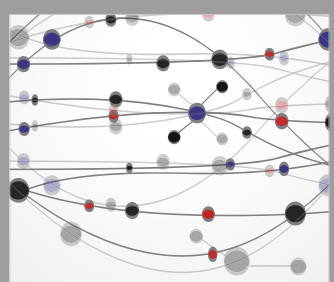

The Scientific World Journal
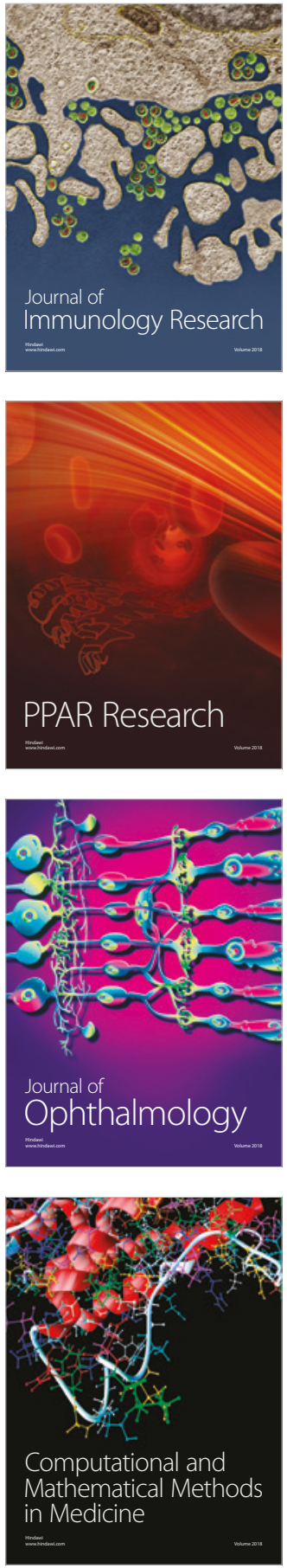

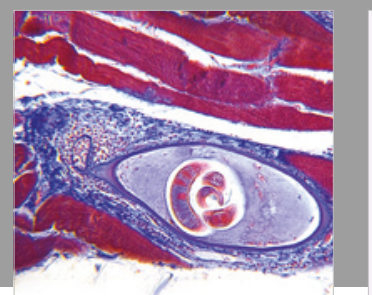

Gastroenterology Research and Practice

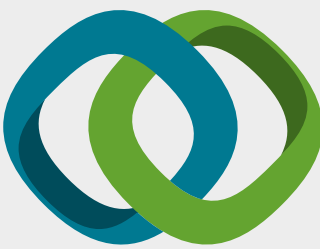

\section{Hindawi}

Submit your manuscripts at

www.hindawi.com
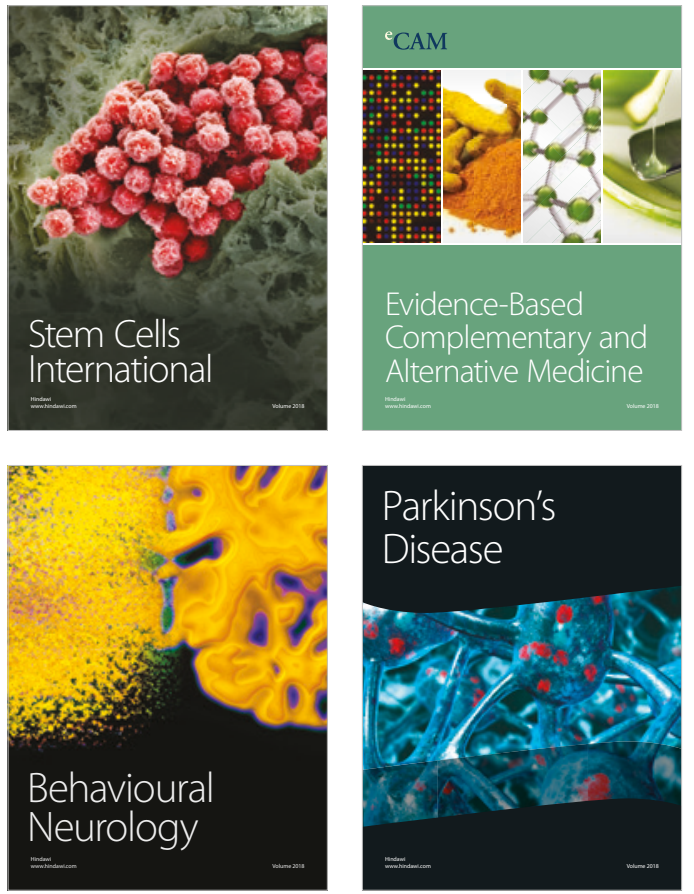

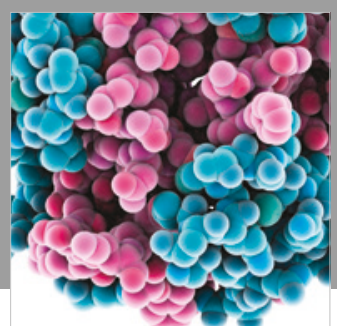

ournal of

Diabetes Research

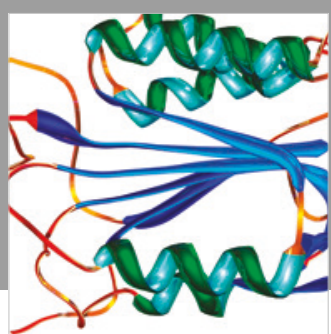

Disease Markers
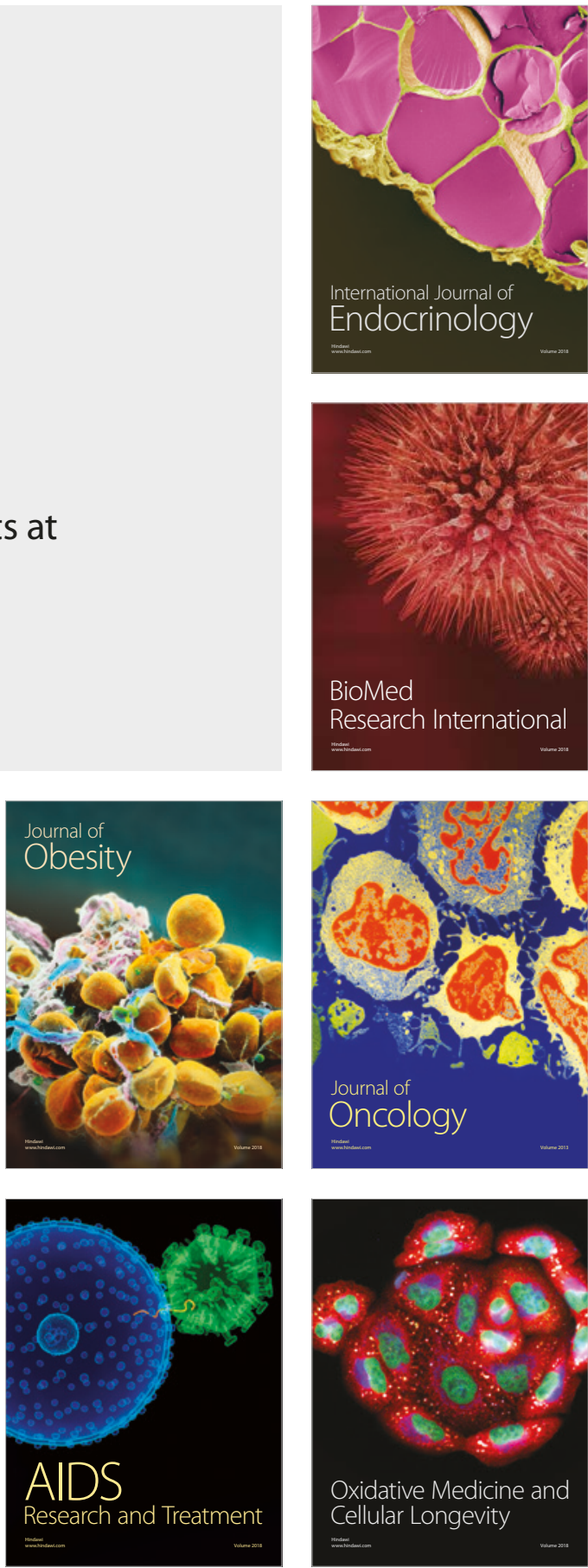